\title{
Editorial
}

\section{Nubarrones sobre el horizonte de El Salvador}

En las últimas semanas se han venido acumulando acontecimientos que están llevando a no pocos a concluir que El Salvador es cada vez menos viable como país. La pasividad del gobierno, la desorientación de los partidos políticos, la indiferencia de la empresa privada, una realidad mundial despreocupada de la suerte de la mayoría de su población y la inexistencia de contrapesos a estas realidades contribuyen a alimentar la sensación de agotamiento nacional. Pareciera como si El Salvador se hubiese quedado sin ideas, sin recursos y sin fuerzas para enfrentar con seguridad y confianza los desafíos del nuevo siglo. En algún momento, su transición de postguerra, que en sus inicios despertó tantas expectativas en sectores sociales importantes, habría perdido el norte, dejando sin concretizar las nuevas realidades anunciadas.

Ante esta situación de agotamiento nacional, en el horizonte se perfila la figura de un dirigente carismático y autoritario como respuesta ideal para romper con prácticas ineficientes y corruptas de larga data y para colocar a El Salvador en la ruta del desarrollo sostenible y de la democracia. Algunos piensan que una salida de esta clase es lo que la situación actual demanda, pero eso es todo menos evidente. La persistencia de graves problemas y la incapacidad de la dirigencia actual para enfrentarlos es incuestionable, pero la alternativa que se propone no lo es.

\section{El Salvador es un país agotado}

La constatación de la incapacidad para eliminar la pobreza con la política económica actual, para asegurar el acceso a la canasta básica y a los servicios indispensables a toda la población y para transformar la democracia formal vigente en otra real, lleva a cuestionar objetivamente si la transición de postguerra no habría fracasado en El Salvador. La apertura de algunos espacios políticos para permitir la participación de la oposición en el quehacer nacional y la libertad de expresión resultan logros que se empequeñecen cuando se 
comparan con todo lo que no se ha hecho. Las expectativas no satisfechas por dicha transición, después de la generosidad y el sacrificio de tantos jóvenes idealistas, acentúa esa sensación de fracaso.

Desde hace algún tiempo, junto a este sentimiento ha venido cobrando forma una alternativa que propugna por una intervención radical y rápida, que saque a El Salvador del marasmo en el cual lo han sumido el capital y la política partidista por igual. Esa intervención sería llevada a cabo por un dirigente carismático y necesariamente autoritario, decidido a poner orden. Más aún, a veces se tiene la impresión que con la indiferencia, la ineficiencia y la corrupción se quiere llevar a la sociedad al borde de la desesperación e incluso provocar brotes de violencia popular. Alimentando el descontento y creando anarquía, se estaría buscando demostrar la necesidad de una salida autoritaria de corte caudillista.

A estas alturas no es posible identificar a este dirigente, ni siquiera es posible predecir de qué círculo surgirá, aunque es más probable que surja de la derecha que de la izquierda. En realidad, es indiferente que provenga de un lado o del otro. Lo determinante no es su lugar de origen, ni siquiera sus antecedentes, sino su capacidad $y$ habilidad personales para ganarse la credibilidad de la población. Objetivamente, las condiciones para el surgimiento de una salida de este tipo maduran con relativa rapidez. De hecho, las encuestas de opinión pública la detectaron hace ya algunos meses. En un momento determinado, la opinión pública llegó incluso a identificar al político que podría asumir este papel; pero las expectativas desaparecieron con la misma velocidad con la que surgieron, porque la perspectiva se reducía a atacar al ex presidente Cristiani y a algunos de sus allegados. Subjetivamente, la frustración y el cansancio prevalecientes han ido preparando el ánimo de la población para dar la bienvenida a una alternativa de esta clase. Esta seguirá masivamente a quien le garantice orden y progreso. El autoritarismo que pudiera implicar sería bien visto, al menos momentáneamente. Sería la respuesta ideal al desorden y la anarquía. La imporencia ante la inseguridad predominante abriga en la mayoría de la gente deseos de venganza y exigencias de mano dura contra los delincuentes.

Es así como El Salvador podría estar a las puertas de una nueva etapa, impredecible, de la transición de postguerra. La sombra del Fujimori peruano, del Menem argentino y del Chávez venezolano se cierne sobre el espectro político salvadoreño. El Salvador se está moviendo en esta dirección, en primer lugar, porque los partidos políticos representan cada vez menos los intereses de la ciudadanía, con frecuencia ni siquiera reconocen sus derechos más elementales. Su credibilidad ha sido socavada por la inoperancia, la ignorancia y la corrupción. El desprestigo en el cual han caído se extiende a todas sus actividades y a las instituciones a las cuales se encuentran vinculados. Esto sucede mientras la vida de la mayoría de la población se debate entre el desempleo, el hambre, la enfermedad y la inseguridad, que abarca un espectro amplio, desde la delincuencia común hasta el transporre público. 
Uno de los vacíos más notables de la transición de postguerra es no haber dotado a El Salvador de la institucionalidad jurídico política mínima para sustentar el cumplimiento de los acuerdos de paz y las reformas sociales indispensables, garantía de una democratización real. La transición debió haber puesto los fundamentos de esta institucionalidad de la cual El Salvador carecía. Es notorio que incluso las pocas instituciones nuevas, creadas a raíz de los acuerdos de paz - como la Procuraduría para la Defensa de los Derechos Humanos, la Policía Nacional Civil y el Consejo Nacional de la Judicatura-, se encuentren bajo el ataque implacable de fuerzas oscuras que se oponen a los cambios más elementales. Un sector del capital, algunos ideólogos de la derecha y algunos medios de comunicación social se han dado a la tarea de socavar las institucionalidad surgida de dichos acuerdos, por la sencilla razón de que promueven la democratización. El que estos primeros pasos hacia la institucionalidad hayan sido tímidos no ha sido óbice para disminuir la intensidad del ataque. No obstante, el proceso ha dado muestras de resistencia singular y no ha podido ser anulado como sus enemigos quisieran. Al contrario, esas instituciones se han convertido en campo de batalla entre quienes propugnan por la democratización y quienes se oponen a ella. Sin embargo, esta lucha ha impedido la consolidación de estas instituciones y la ampliación de su influencia.

La carencia de una institucionalidad básica explica la problemática política y la violencia actuales, que los medios de comunicación social se encargan de exagerar, proyectando así una imagen de caos y desorden. La reacción esperada de la opinión pública es reclamar orden y autoridad. Frente al desorden de la delincuencia común y la violencia generalizada, la solución autoritaria se presenta como una necesidad inevitable y desable. Pero quienes la promueven pretenden ir más allá y extenderla a todos los ámbitos de la vida nacional. La delincuen- 
cia común y la violencia serían un pretexto para implantar de nuevo un régimen autoritario que pusiera fin al proceso de transformaciones que arranca de los acuerdos de paz.

La primera reacción de la población ante el descrédito de la clase política ha sido la abstención electoral, pero ésta no ha reaccionado de manera positiva, sabiendo que aún cuenta con los votos suficientes para continuar en el poder. El monopolio que detenta del aparato electoral neutraliza, en la práctica, las posibilidades para introducir los cambios necesarios por esta vía. Entonces, es cuando en la conciencia colectiva se comienza a perfilar una alternativa de naturaleza distinta. En el pasado reciente fue un régimen autoritario, pero de corte militar; en la actualidad, sería un régimen también autoritario, pero encabezado por un dirigente, en el mejor de los casos, comprometido con la transformación de la sociedad. En circunstancias extremas, esta alternativa no excluye la restauración del orden prevaleciente antes de la guerra de 1980, ni el golpe de Estado. En cualquier caso, para prosperar, debe contar con el apoyo tácito del ejército.

El surgimiento de varias candidaturas independientes en los sectores de la derecha para las elecciones de diputados del próximo año es un intento que busca al mismo tiempo denunciar y romper el monopolio que los partidos políticos poseen del proceso electoral. El mero surgimiento de estas candidaturas cuestiona el papel de éstos como únicos canales de representación ciudadana y es una manifestación palpable del reducido espacio que existe en su interior para el pluralismo y ya no se diga para la disidencia. En los partidos políticos sólo hay espacio para el pensamiento único - y por lo general raquítico- de su dirigencia. El consenso se consigue por imposición desde arriba, sin posibilidad para la discusión abierta o la alternativa. Independientemente del destino que estas candidaturas tengan, deben ser interpretadas como el deseo expreso de un determinado sector social por democratizar la elección de diputados y concejos municipales. Es un reclamo social insoslayable contra los directores de la política nacional para sacar la elección de los representantes de la ciudadanía del ámbito de las cúpulas partidarias y colocarla en el individual, donde es posible ejercer un mayor control sobre los candidatos, los diputados y los concejos municipales. Lo que debiera contar es la persona, sus cualidades, su formación, su trayectoria y su compromiso con la población a la cual pretende representar y no el partido polírico que, en cuanto tal, asume y concentra esa representación, en la actualidad. De hecho, en las últimas elecciones locales se puede observar cómo los electores son capaces de hacer una distinción sutil, pero importante, entre la persona y el partido político.

El agotamiento político de la derecha remite a otra realidad compleja: su proyecto económico. En realidad, los gobiernos de ARENA no han tenido un proyecto económico social propio y el actual no es una excepción. Desde hace algunos años, renunciaron de forma voluntaria a formular una política 
nacional que respondiera a los intereses salvadoreños y, con el pretexto de la globalización, se sometieron dócilmente a las exigencias del capital transnacional. De esta manera, obtuvieron una doble ventaja. La primera es que ya no tuvieron que preocuparse por formular dicha política, lo cual está simbolizado con nitidez en el cierre del Ministerio de Planificación. La segunda es que han descargado toda responsabilidad económica en el mercado mundial, el capital transnacional, los organismos financieros multilaterales y, en último término, en la globalización. Convertidos en simples administradores de decisiones que no controlan, tampoco asumen ninguna responsabilidad. Al delegar en otros la tarea de pensar sobre el curso socio económico de El Salvador, no tiene sentido elaborar planes de largo plazo, ni promover discusiones, ni participar en la toma de decisiones.

Uno de los vacíos más notables de la transición de postguerra es no haber dotado a El Salvador de la institucionalidad jurídico política mínima para sustentar el cumplimiento de los acuerdos de paz y las reformas sociales indispensables, garantía de una democratización real.

Es así como el gobierno salvadoreño no puede garantizar el desarrollo sostenible del país, si por tal se entiende la disminución de la pobreza a niveles inferiores al 5 por ciento. En la actualidad, los pobres salvadoreños representan alrededor del 50 por ciento de la población. Es cierto que la pobreza experimentó una ligera disminución en la primera mitad de la década de los noventa, pero fue una mejora localizada en las zonas urbanas, debida más a la afluencia de fondos externos, en su mayoría provenientes de la asistencia internacional, y que, en cualquier caso, ha remitido, una vez que esa fuente de financiamiento se redujo drásticamente. La reducción de la pobreza exige un crecimiento económico significativo y sostenido, es decir, debe descansar, en lo fundamental, en las estructuras productivas propias. Pero el crecimiento en sí mismo no es suficiente como ha quedado demostrado en la primera mitad de la década de los noventa, cuando la economía salvadoreña creció a un ritmo acelerado. Para reducir la pobreza de manera significativa, la economía debe crecer en los lugares y en las actividades donde los pobres se encuentran concentrados. En consecuencia, el crecimiento experimentado hasta ahora por $\mathrm{El}$ Salvador está mal orientado por lo que toca a los pobres. Algo parecido puede afirmarse del empleo, cuya expansión, en sí misma, no se traduce automáticamente en mayor bienestar. Para ello sería necesario no sólo más empleo, sino mejor calidad del mismo. Dicho de otra manera, con la clase de empleo que se está ofreciendo en la actualidad, no se puede hacer disminuir la pobreza a un nivel tolerable, porque su calidad es mala. 
El agotamiento político de la derecha remite a otra realidad compleja: su proyecto económico. En realidad, los gobiernos de ARENA no han tenido un proyecto económico social propio y el actual no es una excepción.

La derecha neoliberal intransigente considera incuestionable su opción, sin prestar mucha atención a sus consecuencias sociales y políticas. Cree que la marcha hacia la prosperidad está ahora más asegurada y es más veloz por el hecho de haber liberado al Estado de la enorme carga de la planificación socio económica y de algunos servicios públicos. Todavía no parece haber caído en la cuenta que con ello ha propinado un golpe mortal a la actividad política y a lo que pueda haber de democratización, y ha despejado el camino para el surgimiento de formas autoritarias de poder. La tecnocracia neoliberal que rodea al presidente Flores se hace eco de los elementos sociales, políticos y culturales, introducidos recientemente por los organismos internacionales multilaterales en su visión y orientados a matizar el economicismo exagerado que los había caracterizado hasta ahora. Aun cuando estos elementos están subordinados a la perspectiva económica, la diferencia entre las dos visiones es importante. Pero la posición de los tecnócratas es débil y tienen pocas posibilidades de prevalecer sobre el neoliberalismo dogmático. Carecen de la fuerza social y, o política necesaria para imponer su punto de vista. La inversión masiva que El Salvador requiere en infraestructura y en el campo social encuentra un obstáculo insalvable, al menos por ahora, en el bajo nivel de la carga fiscal, la ineficiencia burocrática, la corrupción estatal y privada, la inseguridad generalizada y el deterioro medio ambiental.

Estas circunstancias favorecían la conformación de una oposición política firme y decidida, pero ésta no ha estado a la altura de los desafíos planteados por la transición de postguerra. La izquierda no estaba preparada para sacar provecho del desgaste de la derecha. Entró en la escena política como abanderada de la causa popular y con una aureola de sacrificio y heroicidad, forjada durante el conflicto armado, que funcionaba a su favor; sin embargo, las tentaciones del poder político pudieron más que el compromiso con la liberación de las mayorías populares. Los resabios del dogmatismo guerrillero y las divisiones internas la volvieron hacia sí misma y la alejaron gradualmente de sus bases tradicionales. Al volcarse sobre sí misma, fue perdiendo la visión del país y dejando pasar coyunturas en las cuales pudo impulsar un proyecto popular alternativo de sociedad y Estado, con lo cual confirmó las sospechas de quienes dudaban de su capacidad para gobernar, mientras mantiene alejados de sus filas a muchos que, descontentos con la derecha, buscan un cambio. 


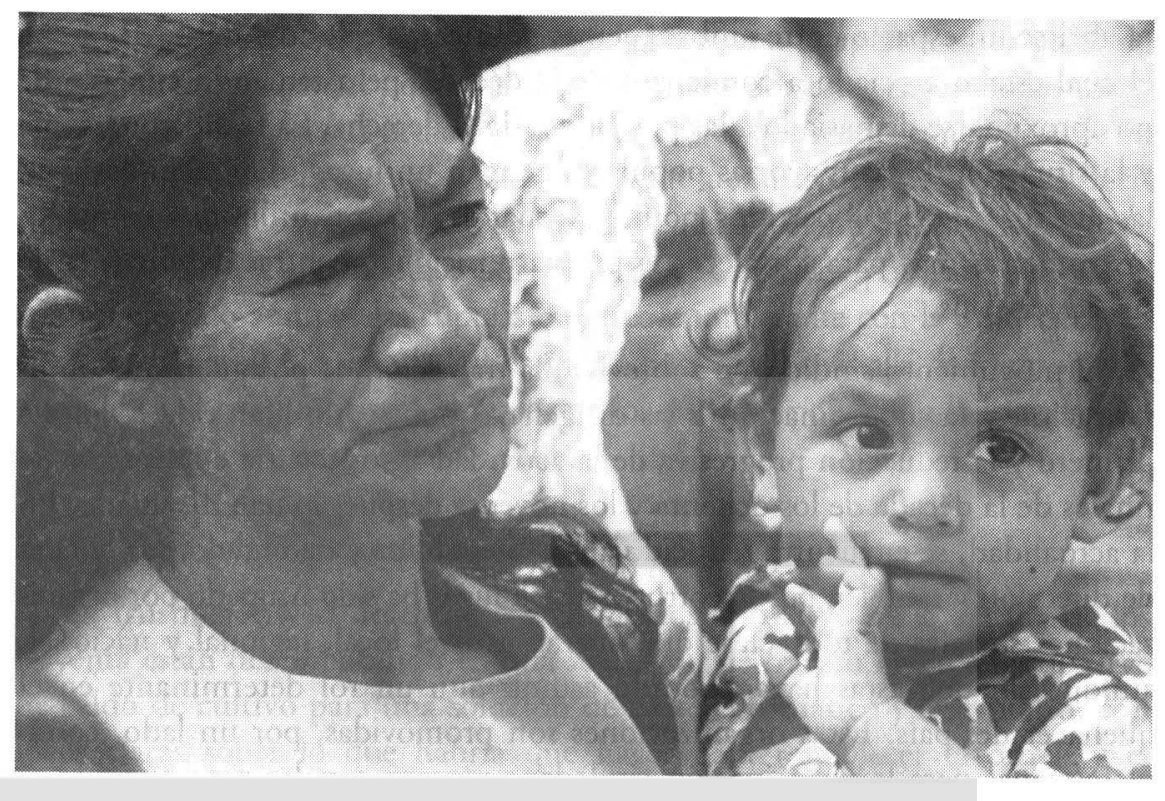

El centro político aspira a convertirse en esa alternativa, pero lleva ya varios años debatiéndose por encontrar su puesto entre los dos polos, constituidos por los dos partidos más grandes. Sin embargo, en la medida en que esos polos frente a los cuales se define se han ido acercando, el centro se ha ido encontrando cada vez con menos espacio. Ensimismado al igual que la izquierda frente a la cual busca tomar distancia, ha carecido de la zagacidad necesaria para constituirse como alternativa política real. Otros enemigos del centro son el tiempo y la tendencia, casi irresistible, a la fragmentación. Aunque en los últimos años ha crecido en las preferencias electorales, está lejos todavía de ser la fuerza que establezca el equilibio. Sus dirigentes envejecen con el paso de las elecciones sin que la generación que los relevará asome en el horizonte. El sobredimensionamiento de su fuerza electoral y el aferramiento a sus prejuicios, además de la ambición personal de su dirigencia, no le permiten consolidarse como el partido que contrarreste la tendencia inevitable hacia la confrontación de los otros dos, frente a los cuales toma posición.

La irrelevancia del quehacer de los partidos políticos está vinculada con la ausencia de un proyecto de país propio. La gerencia de los designios del capital transnacional, que en este momento está a cargo de ARENA, hace irrelevante pensar sobre la problemática de la realidad nacional, inútil la discusión e innnecesaria la voluntad política de cambio. Las dos grandes preocupaciones de ARENA son conseguir que el capital transnacional apruebe su desempeño administrativo y evitar, por todos los medios a su alcance, que el FMLN gane espacios políticos y, eventualmente, que pueda llegar al poder. El FMLN, en el otro extremo, está ocupado en mantener la unidad del partido y en quitar espacio a ARENA y, eventualmente, en desalojarlo del poder. El centro inten- 
ta abrirse un espacio entre ambas fuerzas políticas, alejándose del FMLN con el cual estaba asociado a comienzos de la década, pero teniendo cuidado de no aproximarse demasiado a las posiciones de la derecha. La realidad nacional y la siruación de las mayorías populares ocupan un lugar muy secundario en las agendas de estos partidos políticos, cuando no son utilizados como un instrumento más para fortalecer la propia posición, mientras debilitan la de sus adversarios.

El movimiento sindical no sobrevivió la transición de postguerra. La militarización y la subordinación a las dirigencias político militares de la guerra primero y la reducción progresiva de la actividad agropecuaria e industrial de finales de la década de los ochenta y los noventa después lo han diezmado. En la actualidad, se encuentra reducido al sector público y debilitado por la falta de dirección y también por la corrupción. Su lugar ha sido ocupado por organizaciones sociales de toda clase que operan a nivel local, regional y nacional, aunque sin que éstas hayan podido asumir aún un rol determinante en el quehacer del país. Estas organizaciones son promovidas, por un lado, como plataformas para la participación ciudadana y como canales para que ésta se haga oír y así pueda contribuir a la solución de los problemas. Pero, por el otro lado, están siendo utilizadas para librar al Estado de algunas de sus obligaciones elementales; aunque, en la prácrica, éste se muestra renuente a entregarles los recursos y el poder necesarios para asumirlas plenamente.

En esta descentralización subyace la idea de que estas organizaciones -que toman la forma de asociaciones, redes, coordinaciones, etc.-, al estar más próximas a las comunidades y sus necesidades, pueden atenderlas con mayor eficiencia y prontitud que el Estado. Aunque esta delegación de obligaciones puede ser un agente dinamizador importante de la vida de las comunidades, es discutible hasta dónde aquéllas pueden sustituir a éste, en ámbitos cuya naturaleza es nacional. Con todo, esta tendencia a la descentralización implica el reconocimiento explícito por parte del Estado de su impotencia para satisfacer las demandas de la población. Pero este no es el planteamiento del Estado ni de los partidos políticos salvadoreños, los cuales abrigan serias dudas sobre la conveniencia de la descentralización, porque con ella tendrían que entregar un poder del que hasta ahora se muestran muy celosos. Temen, y con sobrada razón, que ese poder pueda volverse contra ellos, si llegara a desarrollarse.

No cabe duda que la participación ciudadana y la organización de la sociedad, sobre todo aquella orientada a impulsar proyectos locales de desarrollo y de servicios, tienen un potencial democratizador enorme. En los últimos años, en repetidas ocasiones, estas organizaciones han dado muestras fehacientes - aunque todavía esporádicas - de su deseo de influir en las decisiones relacionadas con su propio destino. Estas experiencias han evidenciado no sólo el potencial social de la participación de la ciudadanía, sino también su aspiración a 
constituirse en tal con independencia del Estado, de los partidos políticos y de otras instancias ajenas a sus intereses. El temor a la apertura por parte de quienes monopolizan el poder ha sido reforzado por estas experiencias todavía aisladas. Aun así sus protagonistas han ido adquiriendo conciencia de su fuerza para conseguir que sus demandas sean atendidas e influir en las decisiones que los afectan. Algo se ha avanzado en la selección de los candidatos a los cargos de elección popular por parte de los partidos políticos, aunque el control ejercido aún por las cúpulas es férreo e intolerante con la disidencia. La elección del Fiscal General de la República, postergada más allá de lo razonable, ejemplifica al mismo tiempo el temor de los partidos políticos a la sociedad así como la distancia que los separa de ésta.

\section{Una falsa salida carismático-autoritaria}

La frustración y el desencanto acumulados a lo largo de la década de los noventa están desembocando en una sensación de fracaso nacional, que sirve de caldo de cultivo para una solución de corte carismático y autoritario, con ideas claras sobre lo que habría que hacer para restablecer el orden y el progreso. En esta empresa, carisma y autoridad resultan inseparables. El carisma aglutinaría a las fuerzas a favor del cambio, mientras que la autoridad lo impondría desde arriba y neutralizaría eficazmente a aquellas fuerzas que se le opongan. Sería el retorno a un caudillismo reciclado, cuyos antecedentes se remontan a las dictaduras militares del siglo XX.

Un régimen carismático-autoritario puede resultar atractivo para amplios sectores sociales desesperados, porque simultáneamente niega el orden presente y afirma otro que es su contrapartida casi exacta que, además, se ofrece como realizable en el corto plazo.

En medio de la crisis mundial de 1929, la oligarquía cafetalera entregó la administración del Estado a los militares para que éstos velaran por sus intereses y mantuvieran el orden social, mientras ella se concentraba en engrosar su fortuna. Los militares no sólo cumplieron con la misión asignada, sino que cuando acumularon poder económico, a raíz del conflicto social y armado, entraron a competir en un campo que la oligarquía se había reservado para sí misma. Por ésta y por otras razones que no vienen al caso ahora, el gran capital decidió prescindir de los militares como administradores de la cosa pública y los sustituyó con los políticos. Estos han sido fieles a sus patronos, pero ni los unos ni los otros han sabido guardar el equilibrio indispensable para garantizar la reproducción del modelo, a mediano y largo plazo. A la vuelta de una década, los resultados son alarmantes. La voracidad del capital y la 
visión miope de los políticos se han combinado para crear una situación intolerable, que comienza a ser percibida como un fracaso social.

Este contexto, agravado por el cierre de los canales establecidos para encontrar una salida satisfactoria, es la razón de mayor peso para estimular el surgimiento de un régimen carismático-autoritario. Ahora bien, éste último podría adquirir dos formas, ninguna de las cuales augura nada bueno para $\mathrm{El}$ Salvador. La menos mala sería aquella que utilizase el poder para hacer cambios radicales y rápidos. La segunda consistiría en una vuelta al régimen autoritario anterior a la guerra de 1980, controlado por los militares o por personas afines a éstos. Ambas posibilidades responden al convencimiento cada vez más general de la inviabilidad de la situación actual y de la necesidad de cambios.

A primera vista, esta salida, en cualesquiera de sus dos versiones, presenta algunas ventajas aparentes, en el corto plazo. Sin embargo, un régimen carismáticoautoritario dispuesto a impulsar las reformas estructurales que El Salvador reclama sólo podría tener éxito si surge en una situación revolucionaria y está decidido a institucionalizar dichas reformas. Pero, obviamente, este no es el caso de El Salvador de finales del siglo XX. Por lo tanto, esta alternativa debe ser descartada por irreal. Queda la otra, la de quienes aspiran a reciclar un pasado del cual la transición de postguerra pretendía alejar a El Salvador. El orden que puedan imponer no puede ser duradero, porque al estar basado en la represión, introducirá elementos nuevos de desorden e ilegalidad. El progreso que pueda prometer es muy cuestionable, al menos desde la experiencia recién pasada. Por lo tanto, sería una aventura, cuyo costo, en términos sociales y económicos, es impredecible. El que esta salida sea muy deseada por la población no significa que sea lo que El Salvador reclama, a mediano y largo plazo.

Aun cuando no están dadas las condiciones para un régimen carimásticoautoritario con potencial para transformar radicalmente las estructuras sociales y económicas de El Salvador, es ilustrativo discutir sus posibibilidades de éxito, si dichas condiciones estuviesen dadas. Lo primero que hay que señalar es que no es claro que una salida de esta naturaleza conduzca con certeza a una situación en la cual la vida de la mayoría de la población salvadoreña sea sustancialmente mejor, a un desarrollo sostenible y a una democracia real. Más aún, toda cautela será poca para evitar los riesgos que entraña esta close de solución y es que una vez en el poder, no es fácil mantener la lucidez necesaria para superar las tentaciones que acechan a la conducción personalista. La no prometedora experiencia latinoamericana, en este campo, es una advertencia a tomar muy en serio.

Un régimen carismático-autoritario puede resultar atractivo para amplios sectores sociales desesperados, porque simultáneamente niega el orden presente y afirma otro que es su contrapartida casi exacta que, además, se ofrece como realizable en el corto plazo. Esta atracción se vuelve irresistible cuando, 
una vez en el poder, las primeras acciones confirman que el régimen avanza en la dirección esperada. Estas acciones no tienen por qué ser populistas, aunque es una posibilidad que no debe ser descartada de antemano. El cansancio causado por la indiferencia y la inoperancia de gobiernos pasados hace que tales acciones sean bien recibidas por quienes desean cambios drásticos y rápidos. Si además de satisfacer las expectativas de cambio más obvias, éstas responden a un plan consistente y realista, el respaldo popular y el éxito inicial están asegurados, al menos momentáneamente.

La imposición y la autori-

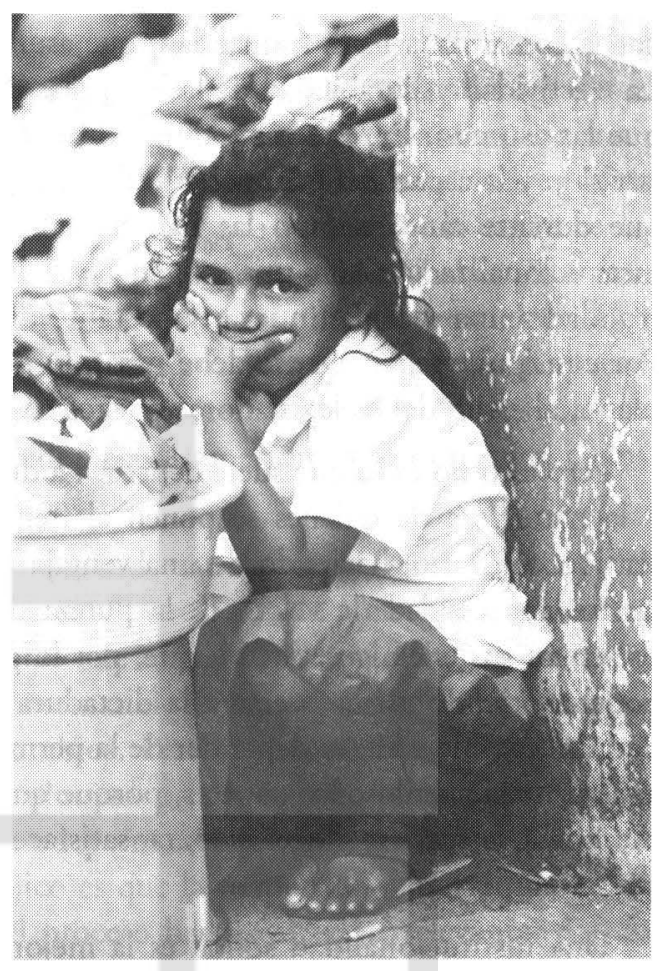
dad, indispensables para lanzar un proceso de reformas radicales y amplias, plantean de inmediato la cuestión del límite. El afán por cambiar, comprensible por el rechazo a la situación presente, lleva, con relativa facilidad, a la arbitrariedad e incluso a la injusticia. Los regímenes carismáticos, por naturaleza autoritarios, son proclives a caer en estos males por concentrar el poder en una sola persona sin ningún contrapeso efectivo, por confiar únicamente en la presunta justeza de su causa y por la simpleza de sus planteamientos. No es fácil trazar la frontera entre la reforma necesaria y justa, y el capricho y la arbitrariedad del dirigente. Si la inseguridad jurídica ha llegado al extremo de convertir la ley en privilegio para el poderoso y en represión para todos los demás, el establecimiento del derecho no puede descansar en arbitrariedades de nuevo cuńo. Eso equivaldría a construir sobre fundamentos débiles y dotaría a los enemigos de los cambios de argumentos deslegitimadores. En la medida en que el proceso de reformas pierda legitimidad tendrá que apoyarse más en la fuerza, si es que quiere mantenerse, pero al final, su desaparición provocará una reacción contraria, que con toda seguridad intentará desmontar los avances conseguidos.

La legirimidad del régimen que impulse este proceso depende, en gran medida, de su fidelidad al planteamiento original, el cual, es obvio, exigirá reajustes. Sin embargo, éstos nunca pueden llegar al extremo de confundir fines y medios, porque eso significaría traicionar el proceso mismo. Por consiguiente, al mismo tiempo que éste se concentra en reformar las estructuras sociales, económicas, políticas y culturales, debe dedicarse con igual intensi- 
dad a construir la institucionalidad, que asumirá su desarrollo y consolidación. La efectividad y durabilidad de las reformas dependerán asi de las instituciones que las asuman. En este caso, quien dirija el proceso sólo sería el agente con la visión y la capacidad para ponerlo en marcha y vencer los obstáculos iniciales, que durante tanto tiempo las han impedido. Las reformas y su simultánea institucionalización son una exigencia, si lo que se busca es construir una realidad y una sociedad nuevas y no tanto dar culto a quien dirige el proceso. Por consiguiente, su agente debe pasar, lo más pronto posible, a un segundo plano, al estilo de los legisladores griegos de la antigüedad.

Pero esto no es lo que suele ocurrir. La dinámica de los procesos históricos y la naturaleza de quienes se ponen al frente de ellos tienden a moverse en sentido contrario, haciendo de una ventaja inicial una desventaja. Argumentando la necesidad de velar por la pureza del proceso y la amenaza que representan sus enemigos, el dirigente, por lo general, tiende a perpetuarse en el poder, abriendo así la puerta a la dictadura personal. Entonces, la continuidad del cambio se hace depender de la permanencia del que sólo debía ser su agente, trastocándose los papeles, porque quien estaba al servicio de las reformas pasa a servirse de ellas para satisfacer, en el mejor de los casos, su ambición personal.

Una institucionalidad sólida es la mejor garantía para un cambio de estructuras radical y duradero. En la actualidad, la democracia pasa por la institucionalidad jurídico polírica, superando aquella otra que se conforma con elecciones periódicas, libres y limpias. Esta clase de democracia se agota pronto si no encuentra instituciones que controlen eficazmente el ejercicio del poder. En este sentido, la institucionalidad presupone una participación social mayor y actúa como freno a cualquier intento por sustituir esa participación por un dirigente. En la medida en que sea real, marca el rumbo al régimen carismático-autoritario, en lugar de que éste se lo marque a aquélla. En efecto, es misión de la institucionalidad velar para que siempre prevalezca el bien común sobre cualquier otro bien o interés y para que el proceso de reformas no se anquilose.

Una democratización real requiere, por consiguiente, una ciudadanía con derechos, que le permita controlar todo aquello que ocurre en la sociedad y en particular las políticas fiscales y sociales como medios para distribuir la riqueza socialmente.

Entender las reformas como un proceso supone dar pasos sucesivos, que agotan etapas, pero que a su vez abren a otras etapas más complejas y superiores. Por lo tanto, se trata de un dinamismo que lanza hacia adelante y abre 
horizontes cada vez más amplios. En este sentido, el proceso posee un alcance mucho mayor que el que pueda proporcionarle un determinado agente o conductor. Este es decisivo a la hora de lanzarlo, pero su desarrollo debe estar asegurado por las diversas instituciones encargadas de concretizar el espíritu reformista. Concentrar el proceso en el agente que lo lanza y lo conduce es limitarlo de antemano. Cuando esto sucede, lo que debiera haber sido una transición de mediano plazo, tiende a prolongarse, incluso con elecciones periódicas, que son invariablemente ganadas por el agente, quien se perpetúa así en el poder, so capa de impulsar un proceso reformista. Las sucesivas reelecciones de algunos de los presidentes sudamericanos son un buen ejemplo de esto.

Como la dirección del proceso depende mucho de la personalidad y del carisma de quien se coloca al frente de él, su dinámica acaba girando alrededor de una sola persona, postergando de manera indefinida la construcción de la institucionalidad, que debería tomar el relevo, una vez rotas las estructuras de poder que impedían los cambios. Pero, por lo general, esta clase de dirigentes no deja el poder por voluntad propia o porque considere haber cumplido su misión, sino porque su permanencia es insostenible o porque simplemente lo echan. Lo paradójico es que la perpetuación del dirigente en el poder, ralentiza la dinámica del proceso hasta volverlo irrelevante. Así, lo que al comienzo actuaba como factor creador de realidades sociales nuevas, luego se vuelve una rémora. La concentración del poder en el dirigente, necesaria para echar a andar el proceso, acaba negando sus mejores posibilidades. Al llegar a este punto, el proceso pierde su razón de ser y su sentido.

Esta salida, para cumplir la misión que se propone, tendría que ir más allá de la apelación tradicional al pueblo. En su nombre asume el poder del Estado de manera autoritaria y en beneficio suyo lo ejerce, para satisfacer sus necesidades y aspiraciones. Pero esta misión no estaría cumplida a cabalidad, sino incluyera la participación popular al decidir aquellas cuestiones que afectan a la mayoría de la población. Este paso ulterior es necesario como afirmación de un derecho que ha sido negado sistemáticamente por los gobiernos, para fortalecer la organización social misma y, cosa muy importante, para garantizar el rumbo del proceso mismo.

En la práctica, los gobiernos han negado los derechos civiles — la igualdad real ante la ley_, políticos — pertenencia a una misma comunidad sin exclusiones de ninguna clase, garantía absoluta para ejercer esos derechos ciudadanos, a través de instituciones específicas, y la existencia de un espacio público-y sociales - garantía de una vida digna y humana - de los ciudadanos, con lo cual han contribuido de una manera determinante a debilitar la organización social y la participación ciudadana. Por consiguiente, una organización social robusta y una participación ciudadana eficaz sólo son posibles desde la construcción de una ciudadanía con derechos. El régimen carismático puede 
contribuir a la construcción de una ciudadanía con derechos, si educa a la población en ellos y si abre espacios para ejercerlos. Este primer paso es importante para ampliar el horizonte de la sociedad y de la ciudadanía; pero, en un segundo momento, estos derechos deben ser apropiados activamente por aquéllas. La ciudadanía así entendida es un proceso de construcción continua, que no sólo afirma derechos y desenmascara desigualdades, sino que también descubre otros derechos nuevos. Aquí radica su fuerza para establecer su vigencia y extender su ejercicio a la mayor parte de la población.

Fomentar la construcción de la ciudadanía es un arma de doble filo. Por un lado, brinda un apoyo fundamental para la consolidación y permanencia del régimen reformista. Su respaldo puede llegar a decidir su futuro, dado que su meta es transformar unas relaciones de poder que han permitido a los gobiernos anteriores administrar el Estado en beneficio del gran capital de espaldas a las necesidades de la población. Pero, por el otro lado, la fuerza social de la ciudadanía se deriva de la conciencia de sus derechos y de su disposición a ponerlos en práctica, lo cual puede dificultar su manipulación. Su potencial transformador está en relación directa con la extensión y profundización de esos derechos, aquello mismo que la hace más independiente de toda fuerza que no sea ella misma.

Una democratización real requiere, por consiguiente, una ciudadanía con derechos, que le permita controlar todo aquello que ocurre en la sociedad y en particular las políticas fiscales y sociales como medios para distribuir la riqueza socialmente. Entonces, la participación social es punto de referencia obligatorio para que el proceso de reformas, dirigido carismáticamente, no se desvie de sus propósitos originales. Ella le recordará las veces que sea necesario que está en el poder para construir el bien común, el cual no puede estar divorciado del bienestar de las mayorías populares. Esto no significa adoptar medidas que irresponsablemente hipotequen la viabilidad del país y de esas mismas mayorías; pero sí las convierte en referente obligatorio de todas las decisiones, incluso de aquéllas que puedan parecerles contrarias a corto plazo. Puede que en algunos casos sea difícil distinguir entre el bienestar de las mayorías populares y el populismo, pero lo que sí es claro es la diferencia entre un gobierno para el cual ellas se encuentran en el centro de su gestión y constituyen su razón de ser y aquel otro para el cual son un estorbo tolerado de mala gana. De aquí a proponer una "solución definitiva" para la población sobrante sólo hay un trecho corto.

Para pensar El Salvador y transformarlo en beneficio de la mayoría de su población, garantizando su bienestar material y sus derechos ciudadanos, es necesario abandonar la agenda de los gobiernos de ARENA y de todos los partidos políticos sin exclusión alguna, y colocar en el centro a esas mayorías populares. Para conseguirlo es indispensable ser menos partidista, en cuanto ello significa ser parcial, y más nacionalista, en cuanto ello significa tener 
como horizonte la totalidad. No es problema de un caudillo, sino de transformaciones estructurales de mediano y largo plazo. El caudillo sólo tiene relevancia relativa, porque debe estar al servicio exclusivo de esas transformaciones estructurales.

De lo contrario, la solución carismático-autoritaria puede volverse irresistible; pero sin que ella misma pueda garantizar su propio éxito. Al contrario, todo apunta a que sería una aventura con elevados costos sociales y económicos para El Salvador. La clase gubernamental y política objetará, convencida de la enormidad de los avances conseguidos por la transición de postguerra, que algo así es imposible en El Salvador. Desde hace ya algunos años, en América del Sur, los dirigentes carismáticos han proliferado hasta volverse un fenómeno común y aceptado. Un El Salvador percibido como un país inviable y fracasado, que no ofrece otra salida, no tiene por qué ser la excepción. Las condiciones están madurando rápidamente y con ellas el riesgo de una nueva aventura dictatorial centroamericana.

San Salvador, 28 de octubre de 1999. 